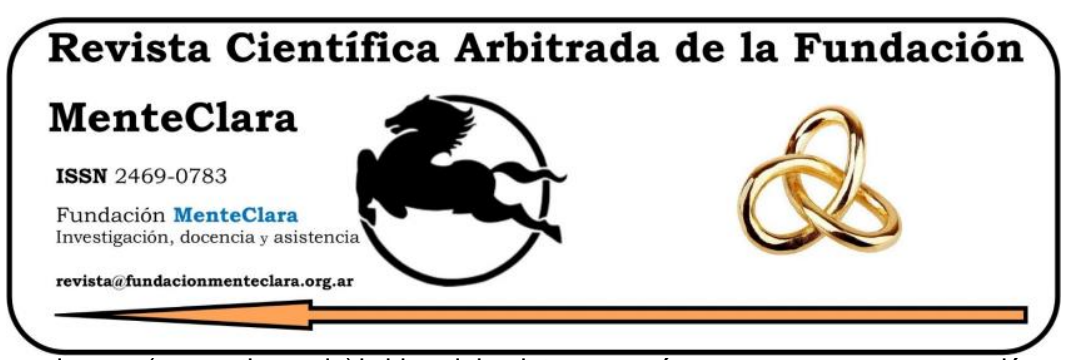

Artículos atravesados por (o cuestionando) la idea del sujeto -y su género- como una construcción psicobiológica de la cultura. Articles driven by (or questioning) the idea of the subject -and their gender- as a cultural psychobiological construction.

Vol. 6 (2021), enero-diciembre ISSN 2469-0783

https: / / datahub.io/dataset/2021-6-e230

\title{
EL INTERÉS EMANCIPADOR DE LA CIENCIA CONTABLE. UN RECORRIDO EPISTEMOLÓGICO
}

\author{
THE EMANCIPATORY INTEREST OF ACCOUNTING SCIENCE. AN \\ EPISTEMOLOGICAL JOURNEY
}

Claudia E. Amézquita M edina Claudia.amezquita@uptc.edu.co Universidad Pedagógica y Tecnológica de Colombia, Programa de Contaduría Pública, Colombia.

Cómo citar este artículo / Citation: Amézquita, C. (2021). El interés emancipador de la ciencia contable. Un recorrido epistemológico. Revista Científica Arbitrada de la Fundación MenteClara, Vol. 6 (230). DOI: https://doi.org/10.32351/rca.v6.230

Copyright: (C) 2021 RCAFMC. Este artículo de acceso abierto es distribuido bajo los términos de la licencia Creative Commons Attribution 4.0 International License (CC BY 4.0). Recibido: 20/06/2021. Aceptado: 29/06/2021 Publicación online: 01/07/2021

Conflicto de intereses: Ninguno que declarar.

\section{Resumen}

Esta breve mirada epistemológica sobre los horizontes ontológicos de la contabilidad pretende desentrañar determinadas convicciones de fondo, inobservables, de tipo filosófico que permitan fundamentar la contabilidad como la ciencia universal del bien común, en desarrollo de la tesis doctoral en ciencias contables de la Universidad de los Andes de Mérida - Venezuela. Se busca el camino hacia la fundamentación y la legitimación de los saberes desde la praxis del sujeto contable, evidenciando experiencias y razones para el cumplimiento de los preceptos de autenticidad, rectitud y veracidad; en las que se libera de los paradigmas racionalistas y lógicos que ha desarrollado la modernidad en el SXX.

Con ayuda de la hermenéutica y la fenomenología se pretende visualizar el horizonte de percepción ontológica y gnoseológica; y a la vez, ha de convertirse en el método, como instrumento emancipador de la técnica contable para garantizar el bien común. 


\begin{abstract}
This brief epistemological look at the ontological horizons of accounting seeks to unravel certain underlying, unobservable philosophical convictions that allow accounting to be founded as the universal science of the common good. The path towards the foundation and legitimation of knowledge and accounting practice is sought, evidencing experiences in compliance with the precepts of authenticity, rectitude and veracity; breaking free of the rationalist and logical paradigms that modernity has developed in the SXX.

With the help of hermeneutics and phenomenology, it is intended to visualize the horizon of ontological and gnoseological perception, which at the same time has to become the method, as an emancipatory instrument of the accounting technique to guarantee the common good.
\end{abstract}

Palabras Claves: Bien Común; Epistemología; Emancipación; Ciencia Contable Keyw ords: Common good; Epistemology; Emancipation; Accounting Science 


\section{Introducción}

"Los filósofos no han hecho más que interpretar de diversos modos el mundo, pero de lo que se trata es de transformarlo" (Marx, 1973).

El mundo en la actualidad, hoy más que nunca, reclama de la contabilidad una atención adecuada al control y al registro del bien común, entendido este en su función de asegurar la calidad de vida en un estado social de derecho y en cumplimiento de los Objetivos de Desarrollo Sostenible para la vida en el planeta. Sin embargo, surge la duda: ¿Podrá lograr la contabilidad un registro y una representación contable para el aseguramiento del bien común; y más, si éste representa un hecho absolutamente peculiar y autónomo, imposible de cuantificar y cualificar?

Este cuestionamiento debe atender los intereses y las expectativas ontológicas y gnoseológicas de la contabilidad como ciencia descriptiva, explicativa e interpretativa, en cumplimiento de los procesos cognitivos de su episteme; los cuales, según Nicolas Hartmann (1986) han de crear el horizonte gnoseológico donde el punto de vista del juicio relaciona el Sujeto y el Predicado en juicios analíticos y sintéticos necesarios para poder conceptualizar, comprender, analizar e interpretar el proceso y la técnica contable para lograr el bien común.

Es aquí, el dónde y el cuándo de la necesidad de crear un método hermenéutico y fenomenológico que permita supeditar los objetos a nuestro pensamiento; es decir, el pensamiento objetivista del sistema económico, por un pensamiento multi-diverso e íntegro, e integral, que logre en todo momento identificar, evaluar y transformar la relación entre 
el sujeto y el objeto contable para asegurar el bien común. El método deberá contener las categorías o conceptos básicos para entender y sintetizar la diversidad de las subjetividades, en un permanente diálogo de intuiciones sensibles, que permitan una significación univoca y pura de la contabilidad como ciencia del bien común. El método deberá presentar un horizonte en el que podamos despejar los siguientes cuestionamientos:

¿Puede la ciencia contable, hacerse cargo de la representación del bien común, a través de una técnica fundamental que trascienda las esferas de las ciencias económicas, sociales y naturales?

¿Podrá una técnica o fórmula contable, asegurar el bien común?

¿Podrá la ciencia contable, superar su dependencia moral y ética, de las esferas normativas que le imponen las politicas económicas actuales?

¿Podrán los contables hacer consciente su responsabilidad irrestricta en el bien común, y de su papel orientador en el esclarecimiento de la realidad que viven las sociedades en vía de desarrollo?; ¿En dónde su dependencia y alienación económica y mediática a las grandes potencias, minan su capacidad y su autonomía científica?

¿Qué pueden hacer los contadores para demostrar su verdadera preocupación y búsqueda de explicación y solución al principal flagelo que mina el bien común: La corrupción?

La respuesta a éstos interrogantes, ha de permitir vislumbrar algunos requisitos para el método fenomenológico que se requiere para hacer de la contabilidad, la ciencia universal del bien común. 


\section{La epistemología contable}

Bajo un enfoque filosófico y epistemológico de la ciencia contable, es fácil vislumbrar las irracionalidades y la sociodicea que se vive en relación al interés público y al bien común. La contabilidad, durante los siglos XIX y XX sólo se ha preocupado por responder a cuestiones epocales y contextuales en torno al sistema capitalista, formando las escuelas como la Contista, la Personalista, la Hacendista, la Controlista, la Patrimonialista, etc., incluso, en su disposición de aquellos campos interpretativos de lo contable: Lo a priori, lo formalizado y lo referido al paradigma de utilidad, igualmente, catalogando; primero como técnica de registro; luego, como campo de conocimiento vinculado a la medición y cálculo del beneficio y, por último, los frustrados intentos de construcción epistemológica de uniformizar un modelo sobre lo Normativo-Positivo.

La contabilidad no ha centrado su episteme ni su accionar en el bien común; sino más bien en el dar cuenta y razón como un arte pragmático y materialista del utilitarismo y la maximización de utilidades, que la ha llevado a la deshumanización, tras una supuesta generación de bienestar y desarrollo económico; sin embargo, lo que se pretende demostrar, es que la contabilidad atiende los postulados de la teoría crítica, centra su fundamento en dar cuenta del bien común y de la sostenibilidad de la vida en el planeta, como su fin universal, fundamental y último como ciencia social de derecho. 


\subsection{Enfoque positivista:}

Los alcances de la ciencia contable bajo el enfoque positivista, han permitido nuevos métodos, procedimientos y técnicas contables, dedicados a resolver problemas; sin embargo, esto no califica como aporte científico, puesto que carecen de la debida racionalidad e hilemorfismo ontológico, epistemológico, teleológico, axiológico y metodológico para lograr el bien común; elementos que le darian rigor científico, validez y confiabilidad a los procesos mediante los cuales se produce cualquier conocimiento derivado de la contabilidad (Casal y Viloria, 2007).

La corriente positivista de la filosofia de las ciencias sociales, no le han permitido a la contabilidad adaptarse a la complejidad del conocimiento para controlar la tecnología y poner a su disposición una técnica que garantice el bien común, no ha hecho nada para evitar la crisis del capitalismo, en donde el dinero catapulta el verdadero valor de las acciones morales, para representar simples valores de uso de mercancías para el goce y disfrute de consumidores acéfalos, embebidos por las ansias de placer capitalista, y que han convertido la contabilidad en una fuente de poder mediático que devela la técnica adquisitiva de bienes como expresión política de riqueza. Una riqueza medida en la propiedad ilimitada de bienes concentrada en unos pocos.

Esta línea racionalista y funcional de la contabilidad es precisamente la que le ha impreso su carácter técnico y operativo, creando la percepción limitada de la ciencia contable como una disciplina satélite del hecho organizacional, limitándose al registro y control de los acontecimientos monetarios y extralimitándose, si entra en los terrenos del criterio o subjetividad del profesional. Por ello la contabilidad se debe desarrollar con miras al cambio paradigmático que permita superar las limitaciones legadas del proceso histórico contable: el empírico, el de la aparición de la partida doble y el del desarrollo del positivismo (Casal y 
Viloria, 2007), desconociendo sus posibilidades como disciplina y ciencia organizacional compleja y de hondo impacto social.

La información contable pasa de tener que dar cuenta de una verdad relativa al bien común, a la representación ciega de una verdad absoluta en la cuantificación sistemática de las operaciones comerciales y tributarias, para garantizar los intereses particulares de las organizaciones. La contabilidad en el positivismo expresa un enfoque cuantitativo de los hechos económicos, en detrimento de la cualificación o explicación amplia y profunda de los mismos.

\subsection{El enfoque legalista:}

Desde sus primeras etapas, la contabilidad ha estado orientada a proporcionar información para los agentes privatizadores de la economía, como son los bancos, los inversionistas, los prestamistas, los proveedores y los aseguradores del capital financiero.

En palabras de Cañibano (1974), la objetividad en contabilidad se comprende en sentido legalista, debido a que todo lo que es representado y valorado se ajusta a efectos jurídicos, los cuales pueden ser considerados como prueba fehaciente, en tanto que el fin último de la información contenida en la contabilidad consiste en la presentación de cifras que den soporte o garantía a usuarios indeterminados.

La significación de la indeterminación de los usuarios de lo contable, se ha quedado en un enfoque legalista, que presupone la aplicación de la ética y la calidad de la información para tomar decisiones de carácter público dirigidas a todas aquellas partes involucradas tanto interna como externamente a la organización; sin embargo, ni la ley ni las normas reglamentarias, han logrado obligar a la contabilidad garantizar con pruebas fehacientes, una información de los hechos económicos que 
asegure la creación del bien común y la sostenibilidad de vida en el planeta.

El modelo de contabilidad pública no responde a demandas de revelación de información en cuanto a dinámicas económicas, patrimoniales, ambientales, sociales y Culturales de la inequidad e ineficiencia del Sistema Tributario en Colombia y la desigualdad en la asignación de recursos. Por ejemplo Ariza (2012) comparte que el Sistema Tributario trae ineficiencias, ya que algunos impuestos indirectos no consultan la capacidad de ingreso de los contribuyentes; así como la inequidad que se origina debido a que la aplicación de algunas tarifas tributarias se da en forma progresiva; también manifiesta que la falta de control constitucional a las disposiciones legales no es igualitaria pues beneficia a unos y perjudica a otros. Desde otro punto de vista Cañas $\&$ Steiner (2013) revelan que la redistribución del ingreso en Colombia es apenas marginal, asî mismo las políticas de transferencias son ineficientes. Por lo cual se infiere que el Estado es "incapaz" de asignar equitativamente los recursos, efectivamente, porque carece de políticas que orienten dicho proceso. Por su parte Hernández, Prada, Ramírez, \& Soto (2000) argumentan que el Sistema Tributario es ineficiente en el sentido de que crea exenciones tributarias para beneficiar algunas inversiones que igualmente sin éstas se hubieran dado, lo que hace más costoso al sistema, además el Estado Colombiano como tal tiene uno de los recaudos de impuestos más bajos de América Latina debido a que los incentivos tributarios se diseñan para estimular el desarrollo sectorial y regional, cuando deberian estar orientados a buscar un mayor crecimiento económico, como en el caso Asiático.

En Colombia, al revisor fiscal se le atribuye la función de dictaminar los estados financieros. Esta labor fue introducida al País por empresarios en el siglo XIX. Años después, desde la expedición de las 
normas reguladoras de la profesión, la jurisprudencia y la doctrina han considerado que la revisoría fiscal es una institución consagrada en las leyes por motivos de orden público.

1.3. El enfoque del cálculo del beneficio:

La Teoría Matemático-Contable de la Contabilidad dentro de la disciplina contable, surge a finales del siglo XIX con el desarrollo de una teoría de contabilidad y álgebra, que considera la cuenta como factor matemático sobre la cual se pueden realizar cálculos. Esta teoría fue desarrollada por Rossi y su fundamento estuvo basado en la igualdad. Se caracteriza por su sencillez y simplicidad. Este es uno de los argumentos para no considerar a la contabilidad como ciencia matemática, dado que el uso instrumental matemático como mecanismo de expresión, no puede definir la naturaleza de una ciencia. Esta teoría considera a la contabilidad como una metodología de observación, la cual se construye teniendo en cuenta postulados de razonamientos matemáticos, sin importar lo que caracterice al objeto estudiado (Álvarez, 2012).

Esta es la principal causa de la deshumanización, ya que la técnica no se configura ni constituye como evidencia de la veracidad de su fundamento y principal postulado: servir al bien común.

La utilización del método deductivo para la obtención de reglas contables, la búsqueda de verdad bajo conceptos de valor razonable como única forma de representar realidad económica sin considerar las externalidades sociales y ambientales, ha llevado a la contabilidad a desestimar el superávit de productividad global que puede beneficiar a todos los participantes para obtener el bien común.

Se crea un sofisma de distracción, en el que el manejo de procesadores de palabra, las hojas de cálculo y recursos gráficos, como utilitarios 
genéricos y la operación de aplicativos de procesamiento electrónico de datos, se convierten en un fin para la contabilidad, pero no se avanza en la búsqueda y organización de información con fines analíticos o de investigación.

1.4. El enfoque de toma de decisiones:

El registro, medición, presentación y revelación de la realidad económica orientada al usuario para proporcionar información útil para la toma de decisiones, bajo el lema de maximización de utilidades, le permitió a la contabilidad desarrollar mejores prácticas de revelación financiera, donde el American Institute Certified Public Accounting, la Comisión Federal de Comercio, el Consejo de la Reserva Federal y la Bolsa de Intercambios de Nueva York, empezaron a formular la teoría contable, como "Verification of Financial Statements", lo cual produjo un énfasis en la atribución de costos e ingresos, descuidando lo concerniente a los activos y su valor.

La teoría de la acción comunicativa de Habermas, y su racionalidad en el ejercicio profesional y el procesamiento de la información contable, requiere, de control del comportamiento de los agen tes y de la los actores en el marco de las decisiones dentro de la organización, requiere de un accionar contable intersubjetivo e interpretativo del lenguaje, del discurso, de las redes de interacción, así como una conciencia ético crítica para medir los efectos directos e indirectos, positivos o negativos de la toma de decisiones en las organizaciones tanto públicas como privadas, para lograr el interés público en el bien común, a través de una técnica científica de base contamétrica y neopatrimonial. 
1.5. El paradigma utilitarista de la contabilidad:

El paradigma de la utilidad de la información muestra la contabilidad como un conjunto interdisciplinario, dado que se apalanca de otras áreas del saber, entre ellas las matemáticas, álgebra, estadística, sociología, psicología, ciencias políticas, investigación operativa y econometría (Santos, et al 1997) (Rojas, 1996). Tanto es así, que puede hacerse una inferencia donde se plantea el paradigma utilitarista como factor que abandona los simples cálculos para encontrar un resultado en las utilidades, por el de brindar cifras detalladas que propendan a una mejor capacidad decisoria por parte de los usuarios de la información.

La intención de reportar información contable, se legitima bajo los parámetros de la utilidad según las condiciones y necesidades del destinatario -usuario-, para la toma de decisiones, eliminando la finalidad fundamental de la contabilidad en pro del interés público, convirtiéndola en una posesión más, de los propietarios, que bajo la normatividad de la junta de normas internacionales, se establece y mejoran los principios de contabilidad generalmente aceptados (GAAPUSA), en interés del público -usuarios o propietarios-, y diluye lo público en lo privado, quedando catapultado cualquier atisbo de democracia contable para garantizar el bien común.

La contabilidad debe tener una voz que se alce de forma libre de los discursos dominantes, debe explorar y explicar las posiciones de utilidad e integridad de una técnica contable para lograr el bien común, bajo la ecología de saberes que le permitan superar el desperdicio de la experiencia y el conocimiento en la ciencia moderna. El paradigma emancipatorio permite al fenómeno humano emerger y ser investigado. 


\section{La sociodicea contable:}

La contabilidad teórica, práctica, y académica, se desempeña bajo paradigmas positivistas, que ensanchan las brechas estructuralistas del conocimiento moderno que la convierten en la sociodicea, que separa lo individual de lo social, lo científico de lo humano, el sujeto del objeto, el ser del pensar, la razón de la cultura, lo económico de lo político.

El doctor Jesús Alberto Suárez Pineda (2018) propone la idea de una ciencia prudencial como una salida a la sociodicea, bajo el paradigma de la complejidad contable, que presupone un cambio drástico en las ciencias sociales, obligándola a observar el caos que genera la globalización en la era digital, y la necesidad de adaptarse a los cambiantes e inciertos paradigmas que emergen de la tecnologia, la información y la comunicación, necesarios para generar conocimiento y crear una ciencia contable que atienda el bien común.

\subsection{En búsqueda del camino emancipador}

Señala el profesor emérito William Leslie Chapman (1965) que "La Contabilidad Social concierne a la recopilación, al ordenamiento, al análisis, al registro, a la sintesis y a la interpretación de los efectos que tiene la actividad de las empresas y otras entidades de la esfera económica sobre el todo social".

"Tales efectos no necesariamente se limitan al ámbitoen el que se encuentra instalado el centro $u$ otras unidades operativas de aquellos entes, sino que también puede extenderse por todo el territorio del pais e incluso trascender al exterior y manifestarse en todo el planeta o, también, más allá del espacio ultraterrestre. Ejemplos extremos de tal amplitud de los efectos de la actividad de aquellos entes, son las empresas que operan en diferentes partes del 
mundo -como por ejemplo las trasnacionales de productos químicos o las empresas de aeronavegación-, asi como entidades como la NASA que extienden su acción a viajes inter espaciales."

Según la Teoría Tridimensional de la Contabilidad la realidad social y ambiental debe reconocerse a partir de su propia condición, fundamentando su importancia en función de su contribución a la armonía naturaleza-hombre-economía y no sólo por su capacidad de contribuir al bienestar del hombre o como proveedora de factores para acrecentar la acumulación económica.

García Casella (2009) considera que los términos riqueza e ingreso no son adecuados para ser utilizados en la Contabilidad Social, por provenir de los enfoques de la teoría económica. Parafraseando el Informe sobre desarrollo humano de 1990 de las Naciones Unidas indica que "la vida extensa, creativa y saludable, reemplazaria a la riqueza desde la Contabilidad económica... señalan que desde Aristóteles el Bienestar Humano es lo que se busca promover en vez de la riqueza en sentido económico". ¿Debe entonces la contabilidad crear una técnica eficaz, que dé cuenta de una teoría y un modelo capaz de construir conocimiento y redimensionar las relaciones económicas, sociales y ambientales para lograr el bien común y el interés público de las sociedades en vía de desarrollo?

Afirma categóricamente García Casella (2009) "queda claro que ninguna persona actúa exclusivamente como homo-economicus, o sea $100 \%$ por motivos económicos. Llegando a la realidad empírica encontramos que hay gran diversidad de motivos de la actividad humana, no exclusivamente económicos. Las metas humanas en sociedad son múltiples y el conjunto de ellas es prioritario; tal vez tenga algo que ver el concepto de Bien Común". 
Señala el profesor García Casella (2000) que “debe haber regulación gubernamental en materia contable, para defender el bien común frente a intereses particulares de algunos actores de la actividad contable que pudieran incurrir en abuso de su posición dominante". Por lo tanto, la persona humana dedicada a las tareas de la contabilidad debe ser integro, con una actitud ética y que con su ejercicio profesional contribuya al logro de los objetivos organizacionales ambientales, económicos y sociales que permitan alcanzar el bien común en la sociedad. Sin embargo, el interés emancipatorio de la ciencia contable, debe llevarla a encontrar las técnicas científicas y tecnológicas que permitan aplicar la contametría del bien común, en la ecuación en la que se represente.

\subsection{La reflexividad matemática del cálculo del bien común}

La matematización y la exigencia ética que requiere la ecuación contable del bien común, podría estar rayando en una posición tecnocrática, que coarta el principio conductual de la profesión? Dos polos se han enfrentado en los últimos siglos. El que aboga por la mayor libertad posible y el que defiende la mayor intervención del Estado, concebido éste como la expresión del bien común. La mayoría de los pueblos han rechazado los extremos, pero hay muchos que acogen visiones que llaman socialistas. Los contadores pueden servir a unos $u$ otros. Deben ser conscientes de lo que hacen. No pueden seguir considerando que lo contable es neutro, asocial.

En sus inicios la contabilidad patrimonial, refuerza una forma de propiedad privada, entendido el patrimonio como fortunas heredadas de los padres; en la contabilidad hacendal se refuerza una forma de propiedad como hacienda, que incluía bienes obtenidos en robo y guerra, 
sobre los cuales se generaban derechos reales, de crédito u obligaciones y sus modos de transmisión.

La contabilidad entonces, desde sus inicios, razona en torno a los intereses del entorno económico, social y cultural, que define una razonabilidad, creada por la crisis de la ciencia, convirtiéndose en sociodicea y que ha de ser superada por una ciencia que atienda los fundamentos técnicos para ser, en su hacer de asegurar el bien común.

\section{Materiales y métodos}

Se pretende desarrollar la investigación bajo un enfoque epistemológico, aplicando un método fenomenológico para definir la contabilidad como ciencia universal del bien común, e identificar su proceso cognitivo desde la praxis del ser y del deber ser contable.

Dentro del grupo de investigación GISOC del programa de contaduría pública de la Universidad Pedagógica y Tecnológica de Colombia en la Facultad Seccional Sogamoso, se ha venido abordando el fenómeno del bien común en la praxis contable a través de los métodos cartográfico, alfabético y discursivo, obteniendo algunos resultados que permiten conocer y controlar el proceso investigativo desde la fenomenología, la hermenéutica y las nuevas epistemologias del sur.

El método fenomenológico a desarrollar, tiene como fin último, identificar los elementos axiológicos que trasciendan o superen los problemas de la ciencia; que de acuerdo con Habermas (1984) cuando sostiene que las ciencias positivas comparten con la tradición de la filosofia el concepto de teoría, pero destruyen su pretensión tradicional: el primero, el sentido metódico de la actitud teórica; y segundo, el presupuesto ontológico de una estructura del mundo independiente del sujeto cognoscente; ya que, se pierde la ligazón fundamental, válida 
desde Platón hasta Husserl, entre theoría y Kosmos, entre mimesis y bios theoretikos. Por tal motivo, un método fenomenológico aplicable, deberá proveer los mecanismos e instrumentos necesarios para dar cuenta de las relaciones intersubjetivas entre seres y entes contables, empleando ciencia de datos y una tecnología de alto impacto en la sociedad globalizada y digital, para asegurar la contabilidad del bien común.

El método cualitativo se aplica para validar la cientificidad de la ciencia contable y orientar la identificación, la autenticación y la autorización de las evidencias, que le permitan su legitimación epistemológica, encontrando las tendencias y las percepciones intersubjetivas de su objeto, en el que se construya colectivamente su filosofia y su razón de ser, en garantizar el bien común y la sostenibilidad de la vida en el planta.

La investigación se inicia con el levantamiento de los procesos técnicos, normativos y políticos que requiere el proceso contable, para posicionar a la contabilidad como ciencia universal del bien común, y debe culminar en un proyecto próximo en el que se institucionalice un mecanismo contable del bien común.

"las intuiciones son ciegas sin los conceptos" y, por otro lado, "los conceptos están vacios sin las intuiciones" (Kant, 1996)

\section{Resultados Esperados}

El fenómeno cognitivo del ser contable frente a su responsabilidad con el bien común, ha de ser estudiado y analizado bajo la concepción antropológica de la profesión, que permita establecer la ecuación contable del bien común. 


\section{Discusión}

El recorrido presenta un panorama poco alentador en relación a la función contable de asegurar el bien común, en cumplimiento al precepto de mantener en marcha los negocios empresariales; ya que, todo acto económico afecta la biósfera y por ende, al mundo entero.

El resultado pondrá en tela de juicio las concepciones morales y éticas del contador público, en relación al proceso cognitivo y teórico práctico de la contabilidad para garantizar el bien común.

Igualmente, la útopia que supone el bien común se une con la útopia de una ciencia contable que ha de contextualizar y situar, en cada comprobante contable, los indicadores para el logro de los ODS.

\section{Conclusiones}

El recorrido epistemológico por la filosofia de la ciencia moderna, nos permite vislumbrar incapacidades y falencias heredadas y enraizadas en lo ontológico de la contabilidad, que no le han permitido al ser contable desarrollar su ética original ni liberarse de los paradigmas de la riqueza líquida: en lo axiológico, de su racionalidad que la limita a la custodia de bienes con valor irracional, y en lo teleológico, porque ha perdido el caleidoscopio que le permita reflectar saberes multidiversos y multidimensionales de la ecología contable para lograr el bien común.

La deconstrucción fenomenológica, posibilita el entendimiento, la comprensión y su interpretación como ciencia comunicativa y situacional en un ideal de discurso para el aseguramiento del bien común y la sostenibilidad de la vida en el planeta; por ello debe: 1) identificar las clases de relaciones inter-teóricas que tiene con otras teorias, 2) analizar su estructura formal, su referencia y su uso, 3) caracterizar sus aspectos semánticos y pragmáticos, y 4) argumentar su nivel de lenguaje 
observacional vs el teórico, en sus múltiples aplicaciones, y por último sintetizar en una técnica sistemática, su extensión epistemológica, psicológica y sociológica para lograr el bien común y la sostenibilidad de la vida en el planeta.

El método fenomenológico ha de permitir visualizar el horizonte del devenir epistemológico de la ciencia contable, para lograr grandes cambios estructurales de pensamiento y conocimiento contable, que exigen nuevas formas de pensar y potenciar el ser ético y creador, para garantizar el bien común y la sostenibilidad de la vida en el planeta. 


\section{Referencias}

Álvarez, H. (2012). Desarrollos teóricos en contabilidad. Revista Visión Contable, N. 10, Enerodiciembre. Págs. 17-50.

Ariza, C. (2012). La ductilidad de los principios constitucionales en materia tributaria. Estudios de Derecho, LXIX (153), 287-314.

Casal, Rosa, \& Viloria, Norka (2007). La Ciencia Contable, su historia, filosofia, evolución y su producto. Actualidad Contable Faces, 10(15),19-28.[fecha de Consulta 30 de Marzo de 2021]. ISSN: 1316-8533. Disponible en: https:/ /www.redalyc.org/articulo.oa?id=25701503

Cañas, A., \& Steiner, R. (2013). Tributación y Equidad en Colombia. Documentos CEDE (24), 1-48.

Cañibano, L. (1974). Teoría actual da la contabilidad. Madrid, España: Editorial ICE

CHAPMAN, William Leslie. (1965). ¿Existe un concepto científico de contabilidad? Buenos Aires: Editorial Centro de Estudiantes de Ciencias Económicas.

GARCIA CASELLA, C.L. (2000). "Curso Universitario de Introducción a la Teoría Contable - Parte Primera” Editorial Economizarte Bs As. ISBN 987-9372-21-1 92 pág.

García-Casella, Carlos Luis (2009). Reemplazo de los conceptos de riqueza e ingreso, no prioritarios en la contabilidad social. En Luisa Fronti de García y Carlos Luis

García-Casella (2009). El sistema contable de gestión ambiental ante el cambio climático, 55-77. Buenos Aires: Universidad de Buenos Aires. Disponible en:

http://www.econ.uba.ar/www/institutos/contable/ centro_social/El_Sistema_Contable_de_ Gestion_Ambiental_ante_el_Cambio_Climatico.pdf.

Habermas, Jurgen [1984]. Teoría de la acción comunicativa. Vol. I. Editorial Taurus. Madrid. España.

Hartmann, Nicolai (1986). Ontologia (trad. ZurGrundlellunll der Ontolollie por José Gaos). Fondo de Cultura Económica. México

Hernández, G., Prada, S., Ramirez, J., \& Soto, C. (2000). Exenciones tributarias: costo fiscal y análisis de la incidencia. Archivos de Macroeconomia (141), 1-30.

Kant, Immanuel (1996). Crítica de la razón pura. Madrid: Alfaguara. Medio impreso

Marx, K. y Engels, F. (1973). Obras escogidas en tres tomos. Editorial Progreso. Moscú. Tomo I.

Rojas, W. (1996). Consideraciones sobre los alcances de la enseñanza de la teoría contable.

Cuadernos de Administración, Universidad del Valle

Santos, G., Durán, M., Urrea, L., \& Urquijo, W. (1997). Acerca de los paradigmas contables. Espacio Estudiantil. Universidad Nacional de Colombia, pp. 141-150.

Suárez Pineda, J. A. (2018). La naturaleza del pensamiento contable. Criterio Libre, 15(27), 43-66. https://doi.org/10.18041/1900-0642/criteriolibre.2017v15n27.1713 